\title{
Sobre a unidade da filosofia de Schelling: uma perspectiva sistemática com base no método construtivo (1801-1810)
}

\author{
On the unity of Schelling's philosophy: a systematic perspective \\ based on the constructive method (1801-1810)
}

Luiz Filipe da Silva Oliveira

luizfilipe3r@gmail.com

(Universidade Federal do Rio Grande do Sul, Rio Grande do Sul, Brasil)

\begin{abstract}
Resumo: 0 objetivo deste trabalho é argumentar que há uma unidade entre os textos considerados pertencentes à parte real e à parte ideal da filosofia de Schelling. Assim, demonstraremos que a principal crítica desferida ao seu sistema da identidade, de não conceber a subsistência do finito em meio ao Absoluto, não se apresentava como um problema sistemático. Pelo contrário, desde o início, pode ser considerada incorporada, não como problema que poderia ser resolvido mediante uma argumentação mais consistente, mas como fundamento de sua filosofia, seja ela da identidade ou liberdade. Isso poderá ser percebido à luz da ideia do Absoluto como meio onde, cientificamente, na parte real, todas as construções eram realizadas e, na parte ideal, sua essência apresentada como vontade de extrapolação do fundo ao qual todas as coisas finitas estavam submetidas mediante sua forma de ser.
\end{abstract}

Palavras-chave: Schelling; identidade; liberdade; sistema; absoluto.

\begin{abstract}
The aim of this paper is to argue that there is a unity between texts considered to belong to the real part and the ideal part of Schelling's philosophy. Thus, we will demonstrate that the main criticism of his identity system, of not conceiving the subsistence of the finite in the Absolute, did not present itself as a systematic problem. On the contrary, from the beginning, it can be considered incorporated, not as a problem that could be solved through a more consistent argument, but as the foundation of its philosophy, be it of identity or freedom. This can be perceived in the light of the idea of the Absolute as a means where, scientifically, in the real part, all constructions are realized and, in the ideal part, where its essence presented as will of extrapolation from the ground to which all finite things are submitted through their form of being.
\end{abstract}

Keywords: Schelling; identity; freedom; system; absolute.

Apesar de crescentes novos esforços em demonstrar a originalidade do pensamento hegeliano desde sua primeira fase em Jena, por um lado, ainda é considerado coerente afirmar que as críticas de Hegel a Schelling no Prefácio da Fenomenologia do Espírito (1807) representam a primeira demonstração pública do abandono hegeliano de princípios fundamentais que caracterizavam a filosofia da 
identidade do filósofo de Leonberg. Por outro lado, sabe-se também que as duras críticas filosóficas de Hegel, amigo a quem Schelling acolhera em Jena, já depois de praticamente ter dado fim às tentativas de conciliação com Fichte, jamais foram bem digeridas. Com isso, é possível considerar que Schelling, naquele momento, ainda nutria certas expectativas em relação à parceria firmada e amizade fortalecida desde 1801, quando Hegel se instalou em Jena, onde Schelling era professor. A qualidade da crítica hegeliana diante de seus próprios princípios é inegável e parece ser consequência de sua incessante busca por aprimorar o princípio especulativo da "identidade da identidade e não-identidade" (Hegel, 2003, p. 95), apresentado primeiramente de modo mais nítido no escrito Diferença entre os sistemas filosóficos de Fichte e Schelling (1801). No entanto, a partir daquilo que discorreremos aqui, indiretamente, poderemos perceber que o mérito de Hegel neste sentido só pode ser medido se encarado como uma alternativa filosófica para um problema no qual o próprio Schelling não acreditava ter apresentado os aparatos teóricos para ser solucionado, pelo menos não conforme se exigia dele. Melhor dizendo, por mais que pudesse ser considerado um problema, não consistia numa crítica cujos fundamentos residiam em alguma inconsistência no sistema schellinguiano. Tal problema dizia respeito à questão de que sua filosofia não seria capaz de explicar a "descendência [Abkunft] das coisas finitas a partir do Absoluto e a relação delas com ele" (Schelling, SW VI, p. 28).

Outros, como Schiller, também haviam compreendido que o problema, que ficou marcado sob a anedota hegeliana da "noite em que todas as vacas são pretas" (Hegel, 1986, p. 22), parecia ser insolúvel à maneira como Schelling apresentara seus princípio até ali, 12 de maio de 1801, quando o poeta envia uma carta a Schelling dizendo: "ainda não posso prever como você irá extrair positivamente seu sistema da proposição da indiferença. Que você tenha feito, não tenho dúvidas, e estou ainda mais ansioso para o desatar do nó" (Schiller, 1948, p. 596). Estamos a dizer que esta exigência específica acerca da possibilidade ou derivação das coisas do Absoluto não se apresentava como um problema imediato à filosofia schellinguiana. Pelo contrário, essas exigências não levam em conta uma série de afirmações públicas de Schelling de que sua filosofia não concebia haver qualquer passagem do infinito ao finito. Isso fica muito bem estabelecido nas Apresentações ulteriores do sistema de filosofia (1802). ${ }^{1}$

\footnotetext{
1 A afirmação acerca da impossibilidade da passagem do infinito ao finito pode ser encontrada em diversas partes da filosofia de Schelling, mesmo em fases diferentes de seu desenvolvimento filosófico. Exemplo mais claro disso aparece nas Cartas sobre o dogmatismo e criticismo (1795) quando afirma que: "A filosofia não pode passar do infinito para o finito, mas, inversamente, do finito para o infinito. 0 esforço para não permitir uma transição do infinito para o finito torna-se assim o meio-termo de ligação entre os dois, mesmo para o conhecimento humano. Para que não haja passagem do infinito para o finito, a tendência ao infinito, o eterno esforço para perder-se no infinito, deve estar presente no próprio finito" (Schelling, SW I, p. 315).
} 
Mas como o pensamento de uma dedução [Ableitung] do finito a partir do infinito absolutamente oposto a ele, ou o que foi chamado em geral de dedução do particular a priori, deve ser considerado como um pensamento completamente impossível, temos apenas que falar daquele conhecimento do entendimento que se vangloria saber e que consiste na mera recondução [Zurückführen] do particular ao universal e do efeito à causa, ou vice-versa (Schelling, SW IV, p. 341).

Um ano antes, em 1801, Schelling publica o texto intitulado Apresentação de meu sistema de filosofia com o intuito alegado de apresentar uma versão definitiva de seu sistema de filosofia, que havia ganhado uma duplicidade figurada, por um lado, através da filosofia da natureza e, por outro, pela filosofia transcendental. A intenção fundamental seria então de unificar estes dois polos mediante o princípio da identidade absoluta. Contudo, diferente do modelo apresentado no Sistema do idealismo transcendental (1800), onde a identidade originária se torna autoconsciente a partir de um processo histórico-relacional entre intuinte e intuído, na filosofia da identidade a identidade originária é concebida como o elemento imediatamente presente a partir do qual o filósofo parte para a construção da finitude. Aquilo que Schelling chamava de "razão, ou razão absoluta" (Schelling, SW IV, p. 114) em 1801 deve ser observada como herança tipicamente espinosana em detrimento do fichteanismo ainda presente até 1800.

A confissão declarada de Schelling de possuir metodologicamente a filosofia de Espinosa como princípio (cf. Schelling, SW IV, p. 113) deve ser vista aqui do mesmo modo como Hegel reiteradamente também utiliza aquela filosofia como critério de contraposição às filosofias parciais, que possuíam ponto de partida individual, com base na reflexão, ou seja, no entendimento. No escrito sobre a Diferença, Hegel chega a dizer que Fichte, por admitir tanto a necessidade da presença subjetiva do filósofo em seu sistema, não pôde ter concebido que Espinosa, aquele que certamente não produziu uma filosofia com ponto de partida individual, pudesse acreditar de fato em seu próprio sistema (Hegel, 2003, p. 35). Em outras palavras, esta instrumentalização da filosofia de Espinosa servia para Hegel e Schelling determinarem de que maneira o princípio especulativo do qual eles se referiam deveria estar atrelado a uma crítica rígida aos programas de dedução e derivação, que necessariamente deveriam pressupor um ponto de partida individual, subjetivo, ou seja, com base naquele que deduz.

Contudo, seria ingênuo acreditar que esta acomodação seria acrítica. Como dissemos, primeiramente ela possui caráter metodológico, ou seja, na crítica às filosofias parciais com base na reflexão, tal como Hegel demonstrou em seu Fé e Saber (1803). Mais especificamente, não há divergências no que diz respeito ao princípio metodológico do qual partiam, ou seja, o Absoluto, um princípio sistemático nãodedutível com o qual eles se contrapunham àquelas filosofias com base na reflexão. ${ }^{2}$

2 A utilização metodológica do princípio de que partiam não significava necessariamente a redução 
A divergência entre Schelling e Hegel a partir de 1802 e 1803 começa a se delinear exatamente no elemento que os distinguiam de Espinosa, a saber, no elemento da idealidade requerida por ambos, mas que inexistia no realismo espinosano. Grosso modo, por esse lado ideal, Hegel começa a pensar numa forma lógico-especulativa que tornasse possível a presença da finitude em meio à realidade do Absoluto e acomodasse a subsistência de ambos sem que precisasse apelar ao método dedutivo. Schelling, por outro lado, mesmo também criticando duramente o mecanicismo dedutivo na filosofia, abre mão completamente de tentar elaborar algo parecido. Marcante para a demonstração da diferença em relação à filosofia de Espinosa foi a inclusão do princípio filosófico que ele chama de construção, exposto mais diretamente no §VI de suas Apresentações ulteriores do sistema de filosofia e numa resenha, no Jornal crítico da filosofia, intitulada Sobre a construção na filosofia, ambos de 1802. A característica principal deste princípio consiste no fato de que:

É apenas um princípio de construção, com o qual a construção é feita tanto na matemática quanto na filosofia. Para o geômetra é a mesma e absoluta unidade de espaço em todas as construções, para o filósofo é a do Absoluto. É, como já mencionado, apenas uma coisa que é construída, ou seja, ideias, e todo o derivado não é construído como uma coisa derivada, mas em sua ideia (Schelling, SW V, p. 134-135).

Como vimos, o ponto de partida é o conceito de construção utilizado na geometria e a possibilidade de trabalhar com intuições puras, válidas universalmente, construídas dentro das formas de espaço e tempo, a saber, construir assim uma intuição pura de um conceito, por exemplo, o de triângulo. Essa ação deveria ser vista como a inscrição do conceito de triângulo no espaço absoluto das intuições puras. Este ponto, como o autor analisa em seu Sobre a construção na filosofia, foi perfeitamente trabalhado por Kant no que diz respeito ao campo da geometria; no entanto, Schelling acreditava ser possível estendê-lo para a filosofia na medida em que ela poderia alcançar uma intuição não-empírica, isto é, intelectual. 0 aspecto positivo da produção, tal qual mostrou o próprio Kant, não era o objeto concreto, mas a possibilidade de construção, isto é, de haver uma intuição pura do conceito deste objeto. À luz de todo desdobramento da possibilidade de uma intuição pura no idealismo pós-kantiano, lançado pela Doutrina da Ciência, aprimorado pela filosofia da natureza do próprio Schelling, essa intuição pura seria caracterizada na filosofia da identidade como unidade de ideal e real. Isto pode ser observado no diálogo Bruno (1802):

Querias restringir a unidade do ideal e do real a um ponto determinado, da maneira que eu te havia demonstrado, e fazer do real um verdadeiro oposto do ideal, enquanto essa oposição é eternamente apenas ideal e mesmo aquilo que determinas como o real é composto apenas em uma unidade de ideal e real, de tal modo que o que nele é o real verdadeiro é essa própria unidade, mas o que nele repousa sobre a

desse princípio ao seu uso exclusivamente metodológico. 
oposição do ideal e do real é apenas determinação ideal do real. Não encontras, portanto, em parte nenhuma, um real puro em oposição a um ideal; mas, no que diz respeito ao intuir em particular, para descobrir que pões, com toda intuição, seja ela qual for, uma unidade do pensar e do ser, basta perguntar a ti mesmo: o que é que intui propriamente quando diz que intui um triângulo ou um círculo ou uma planta? Certamente, o conceito do triângulo, o conceito do círculo, o conceito da planta, e nunca intui outra coisa além de conceitos. Se, portanto, chama de intuição àquilo que em si é um conceito ou um modo do pensar, o fundamento disso é que põe um pensar em um ser; mas aquilo pelo qual o põe não pode ser, novamente, nem um pensar nem um ser; só pode ser aquilo em que ambos, por toda parte, não são distintos (Schelling, SW IV, p. 291-292).

Dentro dos parâmetros schellinguianos, então, "o fundamento da evidência da intuição geométrica" é a "igualdade absoluta do pensar e do ser", que deve ser presumida também pela filosofia (Schelling SW IV, p. 292). Revela-se então que a ação filosófica, logo, todas as demais, deveria ocorrer em meio à realidade absoluta da intuição pura, mas de modo que essa realidade absoluta não esteja em constituição nesse ato, tal como parecia ser o caso com a filosofia hegeliana. Deus, ou o Absoluto, se dá como meio, ou espaço, em que a construção filosófica se realiza, ou seja, não se constrói o Absoluto em si, mas o particular em meio ao Absoluto. Ele não é um princípio que poderia ser deduzido, mas toda produção ideal das diferenças ocorre nele de modo que o que é tematizado na construção é a "apresentação completa da unidade do particular e universal na sua absoluta indiferença" (Schelling, SW V, p. 131). Em relação ao ideal e ao real, ele está como o eterno está para o finito e o infinito, de forma que "finito e infinito são contemplados no eterno, mas não o eterno no finito ou no infinito" (Schelling, SW IV, p. 301).

Partindo desta perspectiva mesmo em 1801, a frase que inaugurava a Apresentação de meu sistema de filosofia é: "Eu chamo de razão a razão absoluta, ou razão na medida em que é pensada como a total indiferença do subjetivo e do objetivo" (Schelling, SW IV, p. 114). A respeito disso, Jürgensen diz: "ela não explica nada porque nada que possa ser explicado ainda é dado" (Jürgensen, 2000, p. 115). Esta é a máxima da razão, ou Absoluto, como meio no qual a construção é realizada. Grosso modo, Schelling estabelece uma estrutura onde a essência da razão é a identidade do ideal e do real como tal, e a forma é a replicação da identidade do ideal e do real como sujeito e predicado. ${ }^{3}$

A proposição $A=A$, pensada universalmente, não diz que $A$ é um sujeito, nem que é um predicado. Em vez disso, o único ser posto através desta proposição é o da própria identidade que é posta de forma totalmente independente de A como sujeito e de A como predicado (Schelling, SW IV, p. 117).

3 “§. 16. Entre o A que está na proposição $A=A$ como sujeito, e o que é predicado (§ 5), nenhuma oposição em si é possível. Pois, na medida em que são sujeitos e predicados, não pertencem à essência, mas apenas ao ser da identidade absoluta, na medida em que pertencem à essência da própria identidade absoluta, não podem ser pensados de maneira diferente. Portanto, não há contradição entre eles" (Schelling, SW IV, p. 121). 
O conceito de "apresentação" [Darstellung] ajuda-nos a compreendermos melhor o que Schelling entendia através das ideias produzidas na construção. Cabenos dizer que ele se afasta de uma interpretação dessas ideias tal qual o modelo ontológico estabelecido por Platão. Em outras palavras, podemos dizer que de acordo com a doutrina de Schelling a possibilidade de a finitude acender em seu processo de construção só pode ser considerada intelectualmente, melhor dizendo, não consistia numa relação que dizia respeito ao próprio Absoluto. Ele resguarda ao conceito de construção apenas a função de apresentar "formas vívidas de cientificidade para a intuição; mas nela o universal e o particular são sempre apenas um" (Schelling, SW V, p. 243), de modo que o particular e o universal não sejam separados um do outro, mas o particular seja construído em meio ao universal, de maneira que o universal se represente nele. Representa desta maneira o universal sempre como se ambos estivessem postos em unidade, como condição de possibilidade, mas distintos ao mesmo tempo. A identidade absoluta que se representa na mediação dos dois momentos do universal e do particular é a que deve ser apreendida pela construção. No particular, os dois momentos diferenciados em si mesmos se apresentam como uma vida dupla, ou seja, distinguem-se, mas são, no entanto, considerados em sua unidade. A evidência disso aparece quando Schelling diz na Apresentação de meu sistema de filosofia que "o Absoluto é assim apenas posto como um Absoluto sendo posto com diferença quantitativa nos indivíduos, mas com indiferença no todo" (Schelling, SW IV, pp. 126-127).

Estamos a dizer com isso que a proposição da indiferença, aquela que Schiller afirmou não poder visualizar como Schelling se livraria, corresponde já aqui àquela concepção do Absoluto como meio a partir do qual as diferenças são construídas, de modo que nelas subsistia essa vida dupla de finito e infinito, subjetivo e objetivo, a partir de onde se configuram as diferenças quantitativas. Este princípio se ancora na perspectiva de que somente diferenças quantitativas podem ser pronunciadas, mas não uma identidade quantitativa, pois a partir desse momento deveríamos então falar de uma indiferença quantitativa, a verdadeira forma, do subjetivo e do objetivo (Schelling, SW IV, p. 128). Melhor dizendo, a diferença se constitui a partir de uma alteração na configuração da presença de subjetivo e objetivo, mas não o Absoluto, isto é, de modo que ele mesmo não pode ser pensado como um ajuntamento de polos opostos ou soma de partes, configuração marcante do modo de pensar do entendimento reflexionante. Só assim poder-se-ia falar da identidade. ${ }^{4}$ Schelling apresenta a identidade como uma "lei suprema para o ser da razão [Seyn der Vernunft], e como não há nada fora da razão, para todo ser (na medida em que

4 Jürgensen ressalta o importante fato de que é apenas "após a determinação da razão como indiferença, [que] segue-se a determinação da identidade. A indiferença é obtida pela abstração da diferença, a identidade pela reflexão sobre a indiferença. Ela não tem partes opostas si mesma nem está dividida, nem a razão é parte nem está dividida: 'A razão é, portanto, uma em sentido absoluto' (SW IV, 116 §3)” (Jürgensen, 2000, p. 118). 
é compreendido na razão)" (Schelling, SW IV, p. 116). Não parece ser sem propósito que ele qualifica a identidade como a lei suprema de todo ser [Seyn], enquanto todo ser está na razão, o que é diferente de dizer que tudo que há na razão é ser. A identidade absoluta é representada exatamente a partir diferença entre "a forma de seu ser, inseparável de seu ser" (Schelling, SW IV, p. 121), e sua essência: “o que é juntamente posto com a forma da proposição $A=A$ também é posto diretamente com o ser [Seyn] da própria identidade absoluta, mas não pertence à sua essência [Wesen], mas apenas à forma ou modo de seu ser" (Schelling, SW IV, p. 120). Deste modo é possível dizer que "o ser pertence igualmente à essência da razão" (Schelling, SW IV, p.118), está numa relação de identidade com ela de modo que pode ser representado segundo a proposição $A=A$, mas que essa, a essência, não se reduz a ela.

O horizonte no qual o Absoluto se apresentava ao filósofo que procedia no método construtivo deve ser observado então em vista da diferença quantitativa persistente naquela intuição, mas orientadora e condição fundamental de todo conhecimento objetivo. Diferente do Sistema do idealismo transcendental, a intenção de Schelling agora é demonstrar que a finitude não pode mais ser autoconsciente de seu fundamento, pelo menos como um ganho teórico do objeto, o Absoluto. 0 movimento não é dedutivo, das coisas finitas a Deus, mas construtivo, as coisas finitas em Deus, - de modo que não é o Absoluto aquilo a que se alcança, mas a forma como algo está no Absoluto, tal como foi demonstrado com a proposição $A=A$. Como diz Paul Ziche, "se tudo deve ser percebido no Absoluto, então já não se vê através desse médium, o próprio médium permanece essencial ao objeto do conhecimento sem se tornar visível” (Ziche, 2011, p. 165). Desta forma, podemos afirmar que "o nome filosofia da identidade esconde, portanto, em vez de esclarecer, que a diferença molda essencialmente o esforço de Schelling para determinar a identidade" (Jürgensen, 2000, p. 113, grifo nosso).

Toda atividade filosófica, desta maneira, deve ser concebida a partir de uma representação fracionada do Absoluto, horizonte no qual todas as coisas são reproduzidas. Como afirma Danz, "na construção filosófica, o Absoluto só é representado indiretamente como um meio no qual a construção se realiza, e não como tal” (Danz, 2017, p. 62). A construção só deve ser possível de um ponto de vista onde já está em si mesma no Absoluto, de modo que a filosofia funciona como um tipo de “"saber primordial' ou Urwissen, um 'conhecimento do conhecimento', que contém em si todos os outros tipos de cognição, como particulares incluídos na cognição 'universal' ou 'absoluta'” (Breazeale, 2014, p. 94). O saber desse processo é o que distingue a construção filosófica, a qual o filósofo alcança através de uma intuição intelectual, do mero conhecimento ao qual estão abandonados os "Brodgelehrte", ou seja, os “eruditos-de-ganha-pão" “destituídos de intuição” (Schelling, SW V, p. 243). Por outro lado, o filósofo com acesso à intuição intelectual, tal como o físico, 
parte de seu princípio, não importando para onde esse o conduza, [de modo que] os fenômenos, caso ele proceda de forma consistente, cairão por si mesmos em seu devido lugar, e o lugar que ocupam no sistema é, ao mesmo tempo, a única explicação que existe para eles (Schelling, SW IV, p. 530).

De modo geral, o importante aqui é a demonstração de que, para a filosofia da identidade de Schelling, Deus, o Absoluto da filosofia, assim como o Absoluto da geometria, não é deduzido nem derivado, e o mesmo acontece com aquilo que dele é representado. Tal como a geometria, a filosofia "não explica", mas "prova que é assim" (Schelling, SW IV, p. 345).

II.

O que dissemos pode ser comprovado à luz da descrição que ele faz posteriormente desse período de seu desenvolvimento, em suas Preleções privadas de Stuttgart (1810), dizendo que aquele, o Absoluto, é o "elemento no qual só a demonstração é possível” (Schelling, SW VII, p. 423). Deste modo, clarifica-se que o foco da filosofia da identidade, em parte, indo na contramão de exigências que eram feitas a ela, por exemplo, a cobrança supracitada de Schiller, antecipando Hegel, não é derivar o finito do Absoluto, mas inscrever o finito no Absoluto e representar nele a identidade absoluta, ou melhor, a própria identidade, no sentido de que, na construção, "o Absoluto não é construído, mas é por excelência” (Schelling, SW IV, p. 140). Seguindo as descrições do método de construção retiradas da geometria, o Absoluto se apresenta como meio através do qual todas as construções em filosofia podem ocorrer, ou seja, a essência, real, em meio a qual a forma, ideal, subsiste, a saber, todas as coisas finitas.

Vemos que essa estrutura se mantém até mesmo em textos mais tardios da filosofia da identidade, por exemplo, em 1804, em Filosofia e Religião, onde costumeiramente diz-se que Schelling revisa pontos fundamentais de sua filosofia, como a interpretação de Morujão (2004, p. 319) que fala de "viragem" e "mutação" na filosofia schellinguiana a partir daquele ano. Schelling segue pronunciando ali que "todo o representar finito é por sua própria natureza apenas ideal, as representações da absolutidade ao contrário são reais" (Schelling, SW VI, p. 34). Deste modo, em continuidade com seus escritos anteriores, é possível dizermos que as preocupações de Schelling estavam voltadas em geral para este Absoluto como horizonte onde todas as coisas, ideias, ou potências, são representações. 0 ponto específico aqui é que a não pronunciação da possibilidade da derivação da finitude em meio à realidade do Absoluto, que o filósofo representa apenas intelectualmente na construção mantendo ainda apenas aquela absolutidade impassível de qualquer carecimento finito - dizia respeito ao modo como o conhecimento teórico pode alcançar a sua 
posição em meio ao Absoluto.

Isso por si só basta para demonstrar a tentativa de Schelling de apostar numa diferença que não se dá através de meios lógico-conceituais como em Hegel, cujo princípio demandava esboçar o espaço da finitude em meio à realidade absoluta, ou seja, identidade e diferença em pé de igualdade. A diferença de Schelling na filosofia da identidade não é pensada nesses termos; o particular e a diferença são pensados “como uma representação do próprio universal” (Ziche, 2011, p. 162). É uma indiferença que subjaz em meio às diferenças e não há ganho teórico por parte do filósofo que não seja encontrar aquilo que se apresenta na distinção entre a forma de seu ser e sua essência, a partir da qual todas as coisas finitas são postas enquanto diferenças quantitativas. Grosso modo, o que a construção fazia era inscrever as diferenças em meio ao Absoluto, enquanto indiferença, através da possibilidade de alcançar a forma de seu ser.

0 resultado alcançado através da filosofia da identidade, bem como sua complementação necessária, que viria nas Investigações filosóficas sobre a essência da liberdade humana (1809), seria posteriormente reconhecido nas Preleções privadas de Stuttgart:

Ora, nós partimos da proposição: a essência originária [Urwesen] é necessariamente e por sua natureza a identidade absoluta do real e do ideal. Mas com essa proposição ainda não se diz nada: temos simplesmente o conceito da essência originária, mas não a temos ainda como uma essência real, efetiva (Schelling, SW VII, p. 424).

A verdade era então que através dos resultados alcançados com a filosofia da identidade descobriu-se o conceito da essência originária, que, conforme foi demonstrado, nunca pode ser alcançada efetivamente pela razão teórica em sua completude em razão da diferença fundamental a que se apresenta no ato da construção. Essa completude só seria mostrada efetivamente então através de uma outra abordagem que não a da filosofia da natureza, a parte real do sistema. Não é à toa que Jaeschke e Arndt dizem que os Aforismos para introdução à filosofia da natureza, datado de 1805, "poderiam ser mais adequadamente descritos como "Aforismos sobre o Absoluto"” (Jaeschke; Arndt, 2012, p. 420). Essas investigações reiteradas sobre a filosofia da natureza, após a publicação da Apresentação de meu sistema de filosofia, foram ressaltadas pelo próprio Schelling na nota prévia das Investigações filosóficas.

Uma vez que o autor, após a primeira exposição geral do seu sistema (Zeitschrift für Spekulative Physik), cujo progresso, infelizmente, foi interrompido por circunstâncias exteriores, se limitou, unicamente, a investigações de filosofia natural, e uma vez que o ponto de partida, no escrito Filosofia e Religião, permaneceu obscuro, certamente por culpa da própria exposição, o presente tratado é o primeiro no qual o autor apresenta, com uma determinação completa, o seu conceito da parte ideal da filosofia; por isso, na medida em que aquela primeira exposição pode ter tido alguma 
importância, deve o autor completá-la, desde logo, com este tratado, que, de acordo com a natureza do seu objeto, deve conter esclarecimentos mais profundos sobre a totalidade do sistema, do que todas as exposições mais parciais (Schelling, SW VII, p. 333-334).

A partir disso, desta forma, podemos encontrar também ali a confissão schellinguiana de que seus escritos até aquele momento se limitaram à parte real de seu sistema, sendo o escrito em questão a primeira dedicação mais clara à parte ideal. De algum modo, essa confissão pode ser interpretada como um certo tipo de acolhimento velado das críticas desferidas por Hegel, contudo, apenas ao mesmo tempo que considerarmos que Schelling mesmo não retroagiu em sua perspectiva, uma vez que podemos visualizar sua filosofia da identidade como essa tentativa de inscrever o finito no Absoluto. Este escrito, trazido à luz após as acusações de Hegel em 1807, na Fenomenologia, deveria ser visto de fato como a parte ideal do sistema, ou seja, como as coisas finitas subjazem, em sua natureza concreta, em meio ao monismo de sistema.

No que diz respeito a essa passagem, da parte real para a ideal, podemos dizer que Schelling colocava sua filosofia na contramão do objetivo buscado na filosofia da identidade sem se contrapor a ela. Novamente suscitando o exemplo do procedimento do geômetra, podemos ver de que modo ocorria essa alteração. Nas Preleções sobre o método do estudo acadêmico (1803), Schelling faz e responde a seguinte pergunta:

O geômetra visa o concreto no círculo (efetivo)? De forma alguma. Mas ele também não visa o mero conceito universal, mas o universal no particular. Portanto, só intui o Absoluto, o absolutamente sem-relação, o círculo em si mesmo, e não o concreto. Mas ele também não despreza o concreto - ele não nega, mas é indiferente a ele (Schelling, SW V, p. 255).

O movimento a ser realizado agora pelo filósofo seria exatamente proceder de modo contrário àquela indiferença que o geômetra, motivado pelo procedimento científico, possuía em relação ao concreto, ao efetivo, que acima dissemos que a filosofia da identidade não encontrava por se tratar de um outro modo de exposição. Grosso modo, até então Schelling estava mais preocupado na demonstração da preservação da absolutidade e não na natureza individual de cada coisa finita. Conforme demonstraremos, por se tratar de um outro modo de exposição, que não negava o primeiro, poderemos afirmar, como faz Ziche, que "as acusações de Hegel contra uma concepção de mediação do conhecimento não interferem, portanto, no conceito de construção de Schelling” (Ziche, 2011, p. 165). Melhor dizendo, elas não chegam a mudar o curso mesmo da filosofia schellinguiana.

A respeito do texto Filosofia e Religião, de 1804, havia ali a tentativa de antecipação do caminho que Schelling percorreria posteriormente em 1809. Já naquele texto Schelling alertava para a tentativa fracassada de elaborar uma série de diálogos que nunca vieram à luz, contendo o mesmo padrão de escrita de seu 
Bruno e o conteúdo de Filosofia e Religião, ou seja, onde transmitiria as mesmas ideias, o lado ideal da filosofia, mas numa outra forma de apresentação (Schelling, SW VI, p. 13). O desenvolvimento incipiente disso fica claro no Bruno quando diz que "o finito, embora de uma forma real e completamente igual ao infinito, não deixa de ser idealmente finito", sendo capaz de tomar para si "uma vida própria" e poder "passar a uma existência diferenciada” (Schelling, SW IV, p. 258). De outro modo, Schelling começa a delinear a possibilidade de as coisas, que são elas mesmas "vivificadas através do seu ser nas ideias", serem capazes de "renunciar àquelas, para si mesmas" (Schelling, SW IV, p. 259).

Schelling começa a elaborar Filosofia e Religião nesse mesmo espírito, de mostrar o lado ideal da filosofia. A motivação mais imediata foi devida a uma querela com Eschenmayer que, numa publicação intitulada $A$ filosofia em sua passagem para a não-filosofia (1803), acreditou que Schelling havia alcançado o ponto alto da razão teórica de explicação do Absoluto, o que então necessitava ser complementada por uma concepção de Deus, inconcebível pela filosofia. Ou seja, Eschenmayer requeria um Deus pessoal, não encontrado pela filosofia schellinguiana, logo, pela filosofia em geral. No entanto, segundo Schelling, tanto a separação de Eschenmayer de Deus e do Absoluto quanto os mal-entendidos de sua filosofia da natureza têm a mesma causa:

Aqueles que querem chegar à ideia do Absoluto através da descrição dada pelo filósofo caem nesse erro quase inevitavelmente, na medida em que apenas obtêm dele um conhecimento condicional, mas a partir de um conhecimento condicional não é possível nenhum conhecimento incondicional (Schelling, SW VI, p. 21).

Desta maneira, o Absoluto não pode ser compreendido através de descrições, uma vez que tais descrições já devem sempre estar em referência à reflexão, ao método dedutivo, a saber, que a partir de um conjunto de descrições se deduziria a realidade do Absoluto. Schelling, então, contrapõe essas formas meramente negativas com o argumento de que o Absoluto só pode ser conhecido pela intuição intelectual. Grosso modo, se dava aqui a compreensão schellinguiana de que o Absoluto que a filosofia da identidade proclamava, mitigada por seu nome, certamente escondia o fato deste não poder ser deduzido como um ajuntamento, tal como de ideal e real, de finito e infinito, de espírito e natureza. Esse princípio aqui é o mesmo apresentado a respeito das diferenças entre a forma do ser da identidade e a essência da identidade enquanto indiferença. Em Filosofia e Religião Schelling aprofunda esse princípio dizendo:

Pois toda descrição do mesmo [do Absoluto] só pode ocorrer em oposição ao nãoAbsoluto, isto é, a tudo que constitui a natureza deste último, a quem vem a ser imputada uma oposição completa, resumindo, a descrição é meramente negativa e nunca leva ao Absoluto mesmo, em sua verdadeira essencialidade (Schelling, SW VI, p. 22). 
As razões para essa posição tem seu fundamento na sua ideia já apresentada do Absoluto como meio, ou seja, que não podia ser afirmado como um ajuntamento de descrições, como um composto, mas que também não se contrapunha a essa ideia em geral, uma vez que toda diferença seria construída mediante a intuição do Absoluto enquanto meio. A origem da separação da ideia de Deus e Absoluto, de onde provinha a distinção entre filosofia e religião, consistia no fato de toda explicação não partir do conteúdo alcançado na intuição intelectual, mas apenas de conteúdos descritivos parciais, o não-Absoluto, opostos à verdade total daquela ideia. Importante ressaltar que mesmo em 1801 Schelling já havia pronunciado que mediante aquela apresentação do Absoluto a fórmula $A=A$ serve apenas para provar a incondicionalidade do conhecimento do Absoluto, mas de modo que este conhecimento mesmo não vem a ser verdadeiramente provado pois é incondicionado (Schelling, SW IV, p. 117-118). Da mesma maneira, tal como a identidade absoluta "é completamente independente de A como sujeito e como objeto" (Schelling, SW IV, p. 130), é mister pensar que ela não poderia ser reduzida à reunião de suas partes. Isso se torna razoavelmente simples de pensar partindo do fato de que as somas das partes que constituem aquela diferença quantitativa entre a forma do ser e a essência, caso levada à identidade, formaria apenas uma identidade quantitativa, o que é distinto da indiferença quantitativa em relação sinonímica com a identidade qualitativa pensada por Schelling. Procedendo desta maneira, como ligamos isso à afirmação de que não há ganhos teóricos do Absoluto? Através do saber da diferença em meio ao horizonte da totalidade, alcançado pelo filósofo na intuição intelectual, ou seja, que the dava acesso à possibilidade da construção da finitude no infinito mediante sua forma de ser, ainda que não de sua essência.

A respeito do Absoluto extra filosófico que Eschenmayer concebia através da não-filosofia, ou seja, da fé, Schelling responderia que tal alcance poderia ser realizado na filosofia mesma. Parece que a análise de Eschenmayer do Absoluto schellinguiano não diferiria da análise que Jacobi fez do panteísmo de Espinosa, retirando-lhe apenas o paralelismo com o ateísmo. Para Eschenmayer, a filosofia deveria ser complementada por algum tipo de teologia da fé. Como dissemos, o método construtivo de Schelling seria a inclusão representativa da existência do ideal em meio ao real, o que a distinguia do realismo espinosano. É isso que ele quis dizer quando afirmou que a filosofia da natureza "expôs, pela primeira vez na ciência, a diferença entre o ser na medida em que existe, e esse mesmo ser, na medida em que é fundamento da existência" sendo "este o ponto no qual ela se afasta de forma mais determinada, do caminho seguido por Espinosa” (Schelling, SW VII, p. 357).

A mera confissão de que a exposição do sistema necessita ser complementada com a parte ideal, unida da asseveração de que isso só se dá "a partir dos princípios de uma verdadeira filosofia da natureza" (Schelling, SW VII, p. 357), demonstra a 
relação ambígua que Schelling nutre para com a filosofia de Espinosa. O que estava posto era que a própria filosofia da natureza, diferente da concepção espinosana, seria capaz de demonstrar a diferença entre o Absoluto, o fundamento da existência, e o ser existente. Como vimos, esta possibilidade era assegurada pelo processo de construção, que garantia a representação do particular no Absoluto. Ao mesmo tempo, desta maneira, a identidade do ideal e do real a que Schelling se refere não poderia ser vista como um processo de unificação realizada pela autoconsciência, mas apenas como meio onde aquela diferença tinha sua condição de possibilidade.

Ora, se na Investigações filosóficas sobre a essência da liberdade humana o passo que ele fundamentalmente dá é dizer que o Absoluto, que ele denomina "nãofundo", não pode ser um produto de opostos, mas de indiferença, "porque, na medida em que se relaciona com os dois como total indiferença, é indiferente em relação aos dois” (Schelling, SW VII, p. 407), então isso não está em oposição ao que foi afirmado mediante o processo filosófico da construção. Tal como Jürgensen descreve a razão apresentada em 1801, "ela medeia a oposição sem se opor a si mesma” (Jürgensen, 2000 , p. 118). A nomenclatura desse meio como identidade absoluta retorna em 1810 nas Preleções privadas de Stuttgart, onde não é interpretado como produto da construção, mas meio através do qual toda construção é realizada: “como alcançamos o conhecimento de Deus ou do Absoluto? Não há resposta a tal pergunta. A existência do incondicionado não pode ser provada como a do condicionado. 0 incondicionado é o elemento no qual todas as demonstrações são possíveis” (Schelling, SW VII, p. 423).

Essa divisão entre condicionado e incondicionado, no contexto da linguagem das Investigações filosóficas, fica bem demarcada:

A distinção entre o fundo e o existente, longe de ser puramente lógica, ou de ser invocada simplesmente como auxiliar para, no fim, ser reconhecida como imprópria, mostra-se, pelo contrário, como uma distinção muito real, que somente a partir do ponto de vista mais elevado pode ser corretamente comprovada e plenamente compreendida (Schelling, SW VII, p. 407).

Esta divisão pode ser vista também como uma resposta de Schelling às acusações de Hegel de que sua filosofia não encontra efetivamente a diferença na identidade, de modo que a identidade na diferença também não pode ser reconhecida como identidade absoluta. Para Schelling, "mesmo que o conceito inscrito no espaço permaneça inalterado, é precisamente na inscrição que o acento da observação é deslocado de 'o quê' para o 'com o quê'; é aqui que deve ser visto o ganho essencial no conhecimento de uma construção" (Ziche, 2011, p. 163). Desta forma, está procurando uma estrutura onde as explicações de cada coisa finita podem ser observadas desde seu ponto de partida, em meio a uma realidade já em perspectiva. Para Schelling, um "adiamento ao infinito do fundamento de explicação” (Schelling, SW IV, p. 358), tal como faz Hegel, colocando o Absoluto no 
final do processo do autoconhecimento do Espírito, não pode fornecer explicações finais que já não devessem estar pressupostas e acessíveis ao filósofo desde o início. Utilizando os argumentos retirados da geometria, mais precisamente com a noção de espaço, onde as formas são construídas, o "womit" ganha validade para a concepção schellinguiana do Absoluto, com o qual o geômetra "não sai do seu Absoluto para chegar ao particular, e a evidência se baseia precisamente no fato de que ele não precisa de nada mais que o Absoluto para demonstrar a unidade particular" (Schelling, SW V, p. 139).

Apresenta-se assim que o Absoluto não consiste num princípio construído diretamente através da construção, mas também não tem uma estrutura especial oposta a ela. Como meio, por sua própria definição, ele não se reduz a um conceito nem pode ser descrito através de um método próprio, seja ele o próprio método construtivo, mas ele mesmo, como espaço, "é toda intuição intelectual" (Schelling, SW IV, p. 279), ou seja, tudo se equaciona nele: "O Absoluto é apenas Absoluto, e o que nele está é necessário e sempre o mesmo, ou seja, necessário e sempre Absoluto" (Schelling, SW IV, p. 374), de modo que "uma coisa individual se torna uma ideia através do mecanismo tautológico de entrada na construção; uma ideia é a coisa individual como está no Absoluto" (Ziche, 2011, p. 164).

Desta forma, em continuidade, ele afirma nas Preleções privadas de Stuttgart:

Assim, mesmo na verdadeira ciência, a razão se comporta como efetivamente passiva, e é a alma que na verdade é ativa. A razão [Vernunft] é apenas a receptiva da verdade, o livro onde as inspirações da alma são escritas, mas ao mesmo tempo, é também uma pedra de toque da verdade. O que a razão não acolhe, o que ela rejeita, o que ela não deixa registrar em si, isso não é inspirado pela alma, isso vem da personalidade. Ela é nessa relação para a filosofia, o que o espaço puro é para o geômetra. 0 que é falso na geometria, um conceito errado, não é admitido pelo espaço, ele o rejeita; por exemplo, um triângulo em que o lado maior é oposto ao ângulo menor (Schelling, SW VII, p. 472).

Essa afirmação do sentido ativo da alma, é precedida por uma outra fundamental de que "a alma é a impessoal", que ela "não sabe, mas é ciência" (Schelling, SW VII, p. 469). Nesse sentido, a alma, como potência suprema da estratificação do espírito humano, sendo impessoal, está conectada com aquele programa "de um mediador [Vermittelnden] para além da consciência" (Ziche, 2012, p. 201) que, da mesma forma que nos textos precedentes, da filosofia da identidade, não recorre ao método de derivação ou dedução do Absoluto. Ou seja, a impessoalidade da alma está diretamente ligada a uma conquista epistêmica. No entanto, uma vez que aparece aquela diferença enfatizada por Schelling anteriormente entre o "existente" e o "fundo", como também entre "alma" e "personalidade", se não quisermos cair numa espécie de movimento unidirecional e epistêmico, diferente do que o próprio conceito do Absoluto como meio pressupõe, é necessário conectar esse duplo movimento com 
a dialética existencial, ética e metafísica apresentada nas Investigações Filosóficas, dedicada à parte ideal do sistema. Nesse sentido, a explicitação da possibilidade de um elemento que acolhe e rejeita as inspirações da alma, conforme a exposição das Preleções privadas de Stuttgart, é fundamental.

III.

Aceitando o princípio de que "nenhum conceito pode ser determinado isoladamente e dado que somente a demonstração da sua conexão com o todo lhe dá a derradeira perfeição científica" (Schelling, SW VII, p. 336), Schelling não considera para o sistema duas opções isoladas como alternativas, mas dois caminhos que coincidem. Contudo, como foi apresentado na filosofia da identidade e visto de modo mais direto nas Investigações Filosóficas, essa coincidência não se dá precedida de uma necessidade. Ou seja, estamos dizendo que desde o início poder-se-ia perceber que essa coincidência não deveria ser concebida como substância morta. No horizonte das construções filosóficas foi demonstrado um Absoluto como meio, no qual toda finitude era construída, ou seja, como elas se encontravam no Absoluto. O que pauta adiante a parte ideal do sistema é exatamente a relação que subjaz o agir humano em meio a esse espaço, ou seja, atividade viva: “Wollen ist Urseyn” (Schelling, SW VII, p. 350).

Sendo as Investigações filosóficas a parte ideal do sistema, Schelling apresenta a realidade não como uma função da razão, tal como se procedia com as construções lógicas e geométricas, mas a partir do campo da personalidade e do espírito. A vontade, esse fundamento metafísico apresentado nas Investigações Filosóficas, não deve ser pensado como um princípio deduzido ao modo como a metafísica clássica, pré-kantiana, achava ser possível alcançar, isto é, como um fundamento exterior, mas sim mediante uma espécie de metafísica crítica, um "movimento transcendente, que só pode ser realizado por seres no mundo" (Gabriel, 2006, p. 7). Essa relação transcendente, intimamente conectada com a relação diferencial, pode ser melhor compreendida quando Schelling passa a relacionar "objeto (Gegenstand) e resistência (Widerstand), como se apenas o modo de se considerar o existente fosse responsável pela diferença: objeto para o intelecto, resistência para a vontade" (Coelho, 2018, p. 24). Schelling compreende essa resistência à vontade como elemento ontologicamente consistente, ou seja, como ser originário da finitude e, logo, do mundo, "pois o mundo também é algo apenas no sentido de que é diferente de outras coisas que ele não é” (Gabriel, 2016, p. 12), ou seja, com o qual ele possui resistência. Posto isso, percebe-se que o fundamento deve ser de um tipo diferente, não pode ser um fundo [Grund], dotado de uma forma de $\operatorname{ser}^{5}$ ao qual se presumiria estar presente no

5 “Em parte alguma se vê que a ordem e a forma eram o originário, mas, pelo contrário, que um 
mundo, mas um "não-fundo [Ungrund] ou indiferença" (Schelling, SW VII, p. 407), ao qual não se pode dizer que exista, uma vez que toda existência [Existenz] deve ter em si um fundo, mas sim o Absoluto exigido para que o mundo apareça como tal. Em outras palavras, não basta a forma do ser no Absoluto, é necessária a mobilização de sua essência, e isso se apresenta como o fundamento da vontade: "Willen zur Offenbarung" (Schelling, SW VII p. 375).

Nesta realidade, sempre há a possibilidade de nos colocarmos numa perspectiva para além do fundo, num movimento de extrapolação ao transcendente, contudo, não de forma que isso nos permita concebermos separados deste fundo, pois "sem o solo do dado [Gegebenen], do mundo, também não estaríamos fora do mundo" (Gabriel, 2016, p. 18), ou seja, sem nossa forma de ser tampouco seríamos nós mesmo. Por isso, é precisamente o dinamismo entre liberdade e dependência que Schelling irá afirmar ser "o motor inconsciente e imperceptível de todo o esforço do conhecimento" (Schelling, SW VII, p. 338). A percepção desta realidade, isto é, esta facticidade na explicação a respeito da origem de todas as coisas é o que nos torna essencialmente humanos, ou seja, finitos. A saber, no sentido de que somos e agimos a partir de um contexto que não pode ser compreendido de forma exata a partir de nossa forma de ser, ou seja, do fundo, e a consciência disso em nossa existência é o que nos torna enquanto tais.

Esta facticidade, que vem à tona a partir da ação defrontada com a resistência à vontade, pode ser visualizada à luz daquela relação diferencial na realidade do Absoluto como meio, conforme apresentada na filosofia da identidade, ou espaço onde todas as construções ocorrem, tal como na geometria ocorria com a ideia do triângulo em geral e o triângulo particular. A incessante busca por extrapolação unida de sua resistência pode assim revelar a natureza sistemática que Schelling sempre teve em perspectiva. Assim, o lado científico e racional da parte real, apresentado mediante o conceito da construção na filosofia, se apresenta como contraparte ao voluntarismo da parte ideal, mas de modo não contraditório. Considerando isso, podemos até mesmo dizer que aquela divisão entre parte ideal e real do sistema não deve ser levada à risca, podendo-se afirmar até que a parte ideal, traduzida nesse movimento de extrapolação pela vontade, dá as condições de possibilidade da busca científica da real, tal como era o papel do filósofo no sistema da identidade, a partir da qual poderia ser alcançada a perspectiva sobre como a ideal tem seu fundamento, a saber, do Absoluto como meio, a partir de onde, como dissemos, não se explica, mas se prova. Como num sistema monista espiritualizado, real e ideal, suas contrapartes se complementam mutuamente de modo que na mais elevada possibilidade de clareza da ciência ainda restaria um momento de mistério.

Percebemos, assim, de que modo Schelling utiliza da própria questão sobre

originário sem regra é que foi trazido à ordem" (Schelling, SW VII, 359). 
a qual ele foi acusado de não ter filosoficamente respondido suficientemente para fundamentar a própria realidade essencial do ser humano. Ou seja, esta realidade reside especificamente no ponto limite, onde a explicação filosoficamente requerida a respeito da derivação das coisas finitas do Absoluto não pode ocorrer. Essa impossibilidade de uma resposta suficientemente apresentada, causada pela diferenciação entre o não-fundo, não reduzível ao mundo do qual partimos, e o fundo necessário a todo existente, manifesta na Investigações filosóficas, bem como nas Preleções privadas de Sttutgart, ou seja, na parte ideal do sistema, unida à noção específica da identidade sistemática apresentada na filosofia da identidade, representa a posição necessária que nos torna humanos, isto é, o impulso a extrapolarmos nossa realidade limítrofe por conter necessariamente algo do Absoluto. Desta forma, percebemos como a parte real do sistema, de onde surgiram as principais críticas ao sistema schellinguiano, foi necessária para a complementação realizada pela parte ideal, de modo que o que está contido em ambas coincide com aquela "vida dupla" sobre a qual o ser humano está fundamentalmente assentado, sendo essa sua verdadeira efetividade.

Assim, ainda que tais textos da parte ideal não possam ser lidos como uma réplica explícita à Fenomenologia, eles contêm uma resposta factual a Hegel, e então, à crítica que ansiava fundamentalmente pela demonstração da subsistência da finitude em meio à realidade absoluta, ou seja, por liberdade. Schelling responde a esse anseio utilizando-se do próprio sentido contido ontologicamente neste anseio, ou seja, através da resistência inerente a ele. Melhor dizendo, todo agir da finitude estava contido num fundamento sobre o qual colocava-se uma perspectiva dupla, qual seja, liberdade e necessidade. O exemplo que Schelling dá afirmando que a sentença “'este corpo é azul', não significa que o corpo seja também azul naquilo em que e por meio de que ele é corpo" (Schelling, SW VII, p. 341) é um prelúdio para a afirmação fundamental de que "a dependência não suprime a autonomia, nem a própria liberdade. Ela não determina a essência; diz só que o dependente, seja ele qual for, só pode ser consequência daquilo de que depende; não diz o que ele é, nem o que ele não é" (Schelling, SW VII, p. 346). Essa perspectiva faz jus à noção apresentada do Absoluto como meio, ou seja, espaço a partir do qual pode-se dizer aquilo "com o quê" as coisas são e a partir de onde elas agem, ou seja, têm seu fundo e sua existência, o "womit", mas não o que são as coisas elas mesmas em sua essência, onde residia aquela indiferença cujas descrições não cabem. Como apresentamos, a natureza desse elemento "com o quê" as coisas são construídas levanos a afirmação derradeira de que, desta forma, é possível dizer com Schelling que o "único dualismo correto" é aquele que "ao mesmo tempo permite uma unidade" (Schelling, SW VII, p. 359). 


\section{Referências}

Breazeale, D. (2014). "Exhibiting the particular in the universal": philosophical construction and intuition in Schelling's Philosophy of Identity (1801-1804) (pp. 91-119). In: Ostaric, L. (Org.). Interpreting Schelling: Critical Essays. Cambridge: Cambridge University Press.

Coelho, H. (2018). O monismo complexificado de Schelling. Cadernos De Filosofia Alemã: Crítica e Modernidade, 23(1), 13-26. DOI: https://doi.org/10.11606/issn.23189800.v23i1p13-26

Danz, C. (2017). "Endlich die Philosophie ist unter diesen Wissenschaften die symbolische.” Anmerkungen zu Schellings Würzburger Symbolbegriff (pp. 55-77). In: Danz, C. (Org. ). Schelling in Würzburg. Schellingiana 27. Stuttgart: frommannholzboog.

Gabriel, M. (2006). Das Absolute und die Welt in Schellings Freiheitsschrift, Bonn: Bonn University Press.

Hegel, G.W.F. (1986) Phänomenologie des Geistes. Frankfurt: Suhrkamp.

Hegel, G.W.F. (2003). Diferença entre os sistemas filosóficos de Fichte e Schelling. Tradução Carlos Morujão. Lisboa: Imprensa Nacional-Casa da Moeda.

Jaeschke, W.; Arndt, A. (2012). Die Klassische Deutsche Philosophie nach Kant: Systeme der reinen Vernunft und ihre Kritik 1785-1845. München: CH Beck.

Jürgensen, S. (2000). Schellings logisches Prinzip: Der Unterschied in der Identität (pp. 113-43). In: Asmuth, C.; Denker, A.; Vater, M. (Orgs.). Schelling. Zwischen Fichte und Hegel. Bochumer Studien zur Philosophie 32. Amsterdam: Grüner.

Morujão, C. (2004). Schelling e o Problema da Individuação (1792-1809). Lisboa: Imprensa Nacional - Casa da Moeda.

Schelling, F. W. J. (1997). Sämmtliche Werke. CD-ROM: Total Verlag.

Schiller, F. (1948). Schiller an Schelling (47) (pp. 596-97). In: Borcherdt, H (Org.). Schiller und die Romantiker: Briefe und Dokumente. Stuttgart: J. G. Cotta'sche Buchhandlung Nachfolger.

Ziche, P. (2004). "Die Seele weiß nicht, sondern sie ist die Wissenschaft". Zum Zusammenhang von Wissenschafts- und Personbegriffen bei Schelling (pp. 199214). In: Buchheim, T.; Hermanni, F. (Orgs.). »Alle Persönlichkeit ruht auf einem dunkeln Grunde«. Schellings Philosophie der Personalität. Berlin: Akademie Verlag.

Ziche, P. (2011). Das System als Medium. Mediales Aufweisen und deduktives Ableiten bei Schelling (pp. 147-68). In: Danz, C.; Stolzenberg, J. (Orgs). System und Systemkritik um 1800: System der Vernunft. Kant und der deutsche Idealismus. Band III. Hamburg: Felix Meiner Verlag.

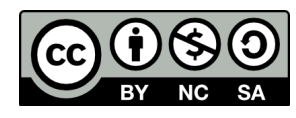

